\title{
BF02, a recombinant TNFR2 fusion protein, alleviates adjuvant arthritis by regulating $T$ lymphocytes in rats
}

Shan-shan SONG, Bei HUANG, Qing-tong WANG, Yu-jing WU, Jing-jing FU, Yun-fang ZHANG, Yan CHANG, Jing-yu CHEN, Hua-xun WU, Di WANG, Ling-ling ZHANG* , Wei WEI*

Institute of Clinical Pharmacology, Anhui Medical University, Key Laboratory of Anti-inflammatory and Immunopharmacology of Education Ministry of China, Hefei 230032, China

Aim: To investigate the therapeutic effects of BF02 on adjuvant arthritis (AA) in rats and the regulatory effects of BF02 on T lymphocyte function.

Methods: SD rats received a single intradermal injection of Freund's complete adjuvant emulsion into the right hind metatarsal footpad. After the onset of AA, the rats were injected BFO2 (1, 3, or $9 \mathrm{mg} / \mathrm{kg}$, sc) every $3 \mathrm{~d}$ for a total of $15 \mathrm{~d}$. Intragastric administration of methotrexate (MTX, $0.5 \mathrm{mg} / \mathrm{kg}$, every $3 \mathrm{~d}$ for a total of $15 \mathrm{~d}$ ) was taken as the positive control drug. Arthritis index, swollen joint count, ankle joint histopathology, spleen histopathology and the paw radiography were used for evaluating the drug effects on AA rats. T lymphocyte function was assessed by measuring T lymphocyte cytokine levels, IL17 and TNF- $\alpha$ mRNA expression levels, and percentage of T lymphocyte subsets.

Results: In the AA rats, remarkable secondary inflammatory responses exhibited, accompanied by significantly higher levels of IL-1, IL-6, TNF- $\alpha$, IL-17, LT $\alpha$, RANKL, and MMP-13. The expression of IL17 and TNF- $\alpha$ mRNAs was also substantially higher than in normal rats. The percentages of $\mathrm{CD}_{3}{ }^{+} \mathrm{CD} 4^{+}$and $\mathrm{CD} 4^{+} \mathrm{CD} 25^{+} \mathrm{T}$ lymphocytes were increased, whereas the percentages of $\mathrm{CD}^{+} \mathrm{CD}_{2} 2 \mathrm{~L}^{+}$and

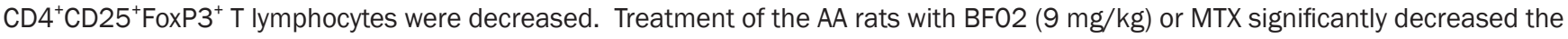
arthritis index, swollen joint count and arthritis global assessment. Moreover, both BF02 (9 mg/kg) and MTX significantly inhibited T lymphocyte proliferation, and blocked the above mentioned aberrance in T lymphocyte cytokine levels, IL17 and TNF- $\alpha$ mRNA expression, and percentages of T lymphocyte subsets.

Conclusion: BF02 exerts therapeutic effects on AA rats via the regulation of T lymphocytes.

Keywords: adjuvant arthritis; inflammation; TNF- $\alpha$; BF02; methotrexate; T lymphocytes; cytokine

Acta Pharmacologica Sinica (2013) 34: 414-423; doi: 10.1038/aps.2012.171; published online 4 Feb 2013

\section{Introduction}

Rheumatoid arthritis (RA) is a chronic progressive inflammatory disease of multi-factorial etiology and a systemic disorder characterized by synovitis, with the subsequent destruction and deformity of joints ${ }^{[1,2]}$. The cytokine TNF- $\alpha$ is central to the inflammatory cascade. It has pleiotropic effects that drive the immune response, with powerful modulatory effects on many aspects of cellular and humoral immunity ${ }^{[3]}$. In synovitis, a large number of immune cells, which secrete plentiful many inflammatory cytokines, such as IL-1, IL-6, and TNF-a, infiltrate the synovium. TNF- $a$ plays a key role in the RA disease process by stimulating synovial fibroblasts to proliferate and produce growth factors, proteases and adhesion molecules ${ }^{[4]}$.

\footnotetext{
* To whom correspondence should be addressed.

E-mail Ilzhang@ahmu.edu.cn (Ling-ling ZHANG); wwei@ahmu.edu.cn (Wei WEI)

Received 2012-08-08 Accepted 2012-11-16
}

Two receptors bind to TNF-a: TNFR1 and TNFR2. Both the pro-inflammatory and the programmed cell death pathways are mainly mediated by TNFR1. TNFR2 has been shown to promote cell activation, migration and proliferation through the activation of the NF-KB pathway ${ }^{[5]}$. TNFR1 and TNFR2 are expressed on different cells and tissues. T lymphocytes express both receptors, especially, TNFR2 is more abundant. TNF-a stimulates $\mathrm{T}$ lymphocytes to proliferate, activate and secrete pro-inflammatory cytokines, such as IL-1 and IL-6, through binding to TNFR $2^{[6]}$.

TNF- $\alpha$ antagonists have revealed their remarkable efficacy for the pathogenesis of $\mathrm{RA}^{[7]}$. Currently, three TNF- $\alpha$ antagonists are available: adalimumab, a fully human monoclonal antibody; infliximab, a chimeric monoclonal antibody ${ }^{[8]}$; and etanercept, a recombinant human TNF-a receptor: IgG Fc (rhTNFR: Fc) fusion protein. rhTNFR: Fc reduces the symptoms of RA, prevents or slows progressive joint destruction and serves as an ideal positive control in RA research ${ }^{[9,10]}$. 
BF02 is also an anti-TNF-a drug. It is a recombinant human soluble fusion protein constructed by the fusion of TNFR2 and the Fc portion of IgG. The purification and synthesis of BF02 were an improvement over etanercept. Therefore, the concentration of BF02 was high, and the generation of isomers has also been effectively reduced.

Rats are immunized with heat-killed Bacillus Calmette Guerin (BCG) in liquid paraffin and subsequently develop AA through a mechanism involving heat shock proteins. AA in rats shares some features with human $\mathrm{RA}^{[11]}$. Therefore, AA is the most widely used model for studies of RA pathogenesis and for the screening of new drugs for the treatment of RA. The contribution of T lymphocytes to AA pathogenesis is well known. The purpose of this paper was to investigate the therapeutic effects of $\mathrm{BF} 02$ on $\mathrm{AA}$ in rats and the regulatory effects of BF02 on T lymphocyte function. Our results indicate that treatment with BF02 inhibits progressive inflammation, reduces $\mathrm{T}$ lymphocyte proliferation and regulates the imbalances in cytokines and $\mathrm{T}$ lymphocyte subsets. These results suggest that the abnormal activity of $\mathrm{T}$ lymphocytes plays a crucial role in the pathogenesis of $\mathrm{AA}$ and that the regulation of T lymphocyte function by BF02 might be one of the mechanisms by which it exerts therapeutic effects in AA rats.

\section{Materials and methods}

\section{Animals}

Male Sprague-Dawley (SD) rats weighing 150 $20 \mathrm{~g}$ were purchased from the B\&K Co, Ltd (SCXK [HU] 2008-0016, Shanghai, China). The animals were housed in a room with a controlled ambient temperature $\left(22 \pm 2{ }^{\circ} \mathrm{C}\right)$ and humidity $(50 \% \pm 10 \%)$, with food and water ad libitum. All experiments were approved by the Ethics Review Committee for Animal Experimentation of the Institute of Clinical Pharmacology, Anhui Medical University (Hefei, China).

\section{Drugs and reagents}

Concanavalin A (ConA) was obtained from Sigma Chemical Co, USA; Dulbecco's modified Eagle's medium (DMEM) was obtained from Gibco Co, USA; $\left[{ }^{3} \mathrm{H}\right]-\mathrm{TdR}$ was obtained from Shanghai Institute of Applied Physics, Chinese Academy of Sciences; anti-mouse PE-CD3, FITC-CD4, PE-CD25, PE-CD62L, PEcy5-Foxp $3^{+}$antibodies were obtained from eBioscience, Inc (San Diego, CA, USA). Primers were synthesized by Sangon Biotech (Shanghai) Co, Ltd. TRIzol and Platinum SYBR Green were purchased from Invitrogen Co. Enzyme-linked immunosorbent assay (ELISA) kits for IL-1, IL-6, TNF-a, LTa, IL-17, RANKL, MMP-13 were purchased from Research \& Development (R\&D) Co, Ltd (USA).

BF02: $16.2 \mathrm{mg} /$ piece (№ 20110518), a soluble human tumor necrosis factor receptor fusion protein, was provided by Suzhou Jinmeng Biotechnology Co, Ltd (China); methotrexate (MTX): $2.5 \mathrm{mg} /$ piece (No 20110106) was purchased from Shanghai CP Xinyi Pharmaceutical Co, Ltd (China); IgG-Fc: 5 mg/mL (No 20110120) was provided by Suzhou Jinmeng Biotechnology Co, Ltd (China).

\section{Induction of AA}

Freund's complete adjuvant (FCA) was prepared by suspending heat-killed BCG in liquid paraffin at $10 \mathrm{mg} / \mathrm{mL}$. The rat AA model was induced by a single intradermal injection of 0.1 $\mathrm{mL}$ of FCA emulsion into the right hind metatarsal footpad.

\section{Treatment of AA}

According to a comprehensive marking of paw swelling, an arthritis index and an arthritis global assessment, the animals were randomly divided into seven groups ( $n=12$ per group): a normal group, a model group, three BF02 groups (which received a 1,3 , or $9 \mathrm{mg} / \mathrm{kg}$ subcutaneous injection every $3 \mathrm{~d}$ for a total of $15 \mathrm{~d}$ ), an MTX group (which received a $0.5 \mathrm{mg} / \mathrm{kg}$ intragastric administration every $3 \mathrm{~d}$ for a total of $15 \mathrm{~d}$ ) and a negative control IgG-Fc group (which received a $9 \mathrm{mg} / \mathrm{kg}$ subcutaneous injection every $3 \mathrm{~d}$ for a total of $15 \mathrm{~d}$ ). After the onset of arthritis, AA rats were administered BF02, MTX or IgG-Fc. Normal and model rats were subcutaneously given an equal volume of saline at the same time.

\section{Arthritis assessment}

From $\mathrm{d} 7$ after immunization, the rats were evaluated every 3-4 d with regard to three clinical parameters: an arthritis global assessment, an arthritis index and the swollen joint count.

The arthritis global assessment of rat AA was based on the symptoms in several regions, such as the ear, nose, tail and paw. The abovementioned cumulative scores were used as the arthritis global assessment, and the maximum score was 8 for each rat ${ }^{[12]}$.

Arthritis index: The severity of arthritis in each paw was evaluated by using a macroscopic scoring system ranging from 0 to $4^{[13]}$. The cumulative score for the three paws with secondary arthritis was used as a polyarthritis index, with a maximum value of 12 .

Swollen joint count: For each paw, five phalanx joints and one ankle or wrist were evaluated for the swollen joint count; thus, the maximum swollen joint count for each rat was 24 for the three secondary arthritis paws and the one primary arthritis paw.

The three above-mentioned arthritis assessment parameters were evaluated on d $0,7,11,15,19,22,25,28,32$, and 35 .

\section{Radiological examination of the paws}

The rats were sacrificed on d 35 after immunization. Both the forepaws and hindpaws of the rats were removed, and bone structures were examined and analyzed by X-ray. The following scoring system was used for the radiological examination: score 0 , no bone damage; score 1 , tissue swelling and edema; score 2, joint erosion and deformation; and score 3, bone erosion and osteophyte formation. The maximum possible score per rat was 9.

\section{Histological examination}

The rats were sacrificed on d 35 after immunization. The 
secondary hindpaws were removed, fixed in $10 \%$ formalin, decalcified in $5 \%$ formic acid, and then embedded in paraffin. Serial paraffin sections were stained with hematoxylin and eosin and were examined microscopically. Pathological changes were evaluated for synovial hyperplasia, cellular infiltration, pannus formation and cartilage erosion under blinded conditions $^{[14]}$.

Hematoxylin and eosin staining of the spleen was performed. Five components were evaluated in the spleen: the cell density of the lymphatic sheath, lymphoid follicular hyperplasia, marginal zone, red pulp, and the total number of germinal centers (GCs) in each section. The grading scheme consisted of ordinal categories ranging from " 0 " (no effect) to " 3 " (severe effect) ${ }^{[15,16]}$.

\section{Assay of T lymphocyte proliferation}

AA rats were sacrificed on $\mathrm{d} 35$ after immunization. The thymus was dislodged under sterile conditions, and thymocytes were collected. The cells were suspended with a lymphocyte separating medium and washed three times with phosphatebuffered saline (PBS). The cell suspensions obtained using the above method $(100 \mu \mathrm{L})$ and ConA $(100 \mu \mathrm{L}$ with a concentration of $3 \mathrm{mg} / \mathrm{L}$ ) were plated onto 96-well plates at a concentration of $1 \times 10^{7}$ cells $/ \mathrm{mL}$ in DMEM with $10 \%$ FBS, in triplicate, and then incubated at $37^{\circ} \mathrm{C}$ (SHEL LAB Co) with $5 \% \mathrm{CO}_{2}$ for $48 \mathrm{~h}$. Six hours before the end of the incubation, $20 \mu \mathrm{L}$ of $\left[{ }^{3} \mathrm{H}\right]-$ TdR was added to each well. The radioactivity was measured by liquid scintillation counter (Beckman Co). The results were described as the average of triplicate counts.

Assay of IL-1, IL-6, IL-17, TNF- $\alpha$, LT $\alpha$, RANKL, and MMP-13 in serum

On d 35, the rats were sacrificed, and the serum was collected from venous blood. The serum was separated from the blood by centrifugation at 2500 rounds per minute for $20 \mathrm{~min}$ and stored at $-80^{\circ} \mathrm{C}$ until use. The levels of IL-1, IL-6, IL-17, TNF-a, LTa, RANKL, and MMP-13 in serum were measured using ELISA kits. The results were expressed as the mean of two wells.

Assay of TNF- $\alpha$ mRNA and IL-17 mRNA with quantitative realtime PCR (qPCR)

Total RNA was extracted from $\mathrm{T}$ lymphocytes using TRIzol reagent according to the manufacturer's instructions. For the PCR reactions, $10 \mu \mathrm{L}$ of SYBR Green was added to $2 \mu \mathrm{L}$ of cDNA with $50 \mathrm{nmol} / \mathrm{L}$ primers in a $20 \mu \mathrm{L}$ reaction, and the PCR conditions were $95^{\circ} \mathrm{C}$ for $30 \mathrm{~s}$, followed by 40 cycles of $95^{\circ} \mathrm{C}$ for $5 \mathrm{~s}$ and $60^{\circ} \mathrm{C}$ for $30 \mathrm{~s}$. A melt-curve was performed from $60^{\circ} \mathrm{C}$ to $95^{\circ} \mathrm{C}$. Sterile distilled water was used to replace the cDNA as a negative control. IL-17 up-stream 5'-ACTAC-

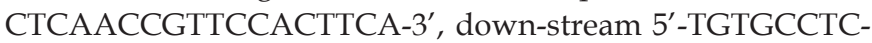
CCAGATCACAGA- $3^{\prime}$. TNF-a up-stream $5^{\prime}$-TTCTCATTCCTGCTCGTGG-3', down-stream 5'-TCCTCCGCTTGGTGGTTT-3'. GAPDH up-stream 5'-ACAGCAACAGGGTGGTGGAC-3', down-stream 5'-TTTGAGGGTGCAGCGAACTT-3'. The GAPDH expression levels were used to normalize gene expression in each experiment. Both the target and normal gene PCR efficiency were first determined by GAPDH to ensure that the normalizing genes were acceptable and to test the primer efficiency. QPCR was carried out on a 2-fold dilution series from a pooled set of $c D N A$, and the threshold $C_{t}$ value was plotted against the log cDNA dilution ${ }^{[17]}$. Expression changes were calculated using the $2^{-\Delta \Delta C t}$ method and expressed as a fold change over the control.

\section{Assay of the subsets of T lymphocytes in the spleen}

On d 35 after immunization, the rats were sacrificed. The spleens were removed, and splenocytes were collected. The cells were purified, suspended with a lymphocyte separating medium, and washed with PBS three times. A $50 \mu \mathrm{L}$ suspension of splenocytes and $10 \mu \mathrm{L}$ of CD3-PE/CD4-FITC, CD25-PE/CD4-FITC, and CD62L-PE/CD4-FITC antibody combinations were added into each fluorescence-activated cell sorting tube.

The samples were mixed gently, incubated for $20 \mathrm{~min}$ at $4{ }^{\circ} \mathrm{C}$, and then analyzed by flow cytometry. The data were analyzed by CellQuest ${ }^{\mathrm{TM}}$ analysis software.

\section{Assay of $\mathrm{CD}^{+} \mathrm{CD}^{+} 5^{+} \mathrm{Foxp}^{+} \mathrm{T}$ lymphocytes in the spleen}

To detect Foxp3 expression, splenocytes were analyzed by three-color intracellular flow cytometry using FITC-CD4, PE-CD25, and PEcy5-Foxp3 ${ }^{+}$antibodies. On d 35 after immunization, the rats were sacrificed. The spleens were dislodged, and splenocytes were collected by a routine method. A $500 \mu \mathrm{L}$ suspension of splenocytes was incubated with both FITC-CD4secific antibody and PE-CD25-specific antibody for $20 \mathrm{~min}$ at $4^{\circ} \mathrm{C}$. After fixation, the cells were permeabilized using a commercially available perm/wash kit for $45 \mathrm{~min}$ at $4{ }^{\circ} \mathrm{C}$. Upon permeabilization, the cells were re-suspended in $100 \mu \mathrm{L}$ of PBS and incubated for $30 \mathrm{~min}$ with the PEcy5-Foxp $3^{+}$antibody. The cells were washed twice with cold PBS and re-suspended in PBS for flow cytometry. The data were analyzed by CellQuest $^{\mathrm{TM}}$ analysis software.

\section{Statistical analysis}

All data are expressed as the mean \pm standard error of mean (SEM). The data were analyzed by SPSS version 11.5 statistical package. Differences between groups were evaluated by a one-way ANOVA and the LSD test. $P$ values less than 0.05 were considered to be statistically significant.

\section{Results}

Effects of BF02 on the arthritis global assessment, arthritis index and swollen joint count

The onset of secondary arthritis appeared on d 11 after immunization. The hindpaws of AA rats swelled initially at $18 \mathrm{~h}$ after immunization; the forepaws swelled slowly, and the swelling peaked from d 20 to d 28. From d 22 to d 25, BF02 (9 $\mathrm{mg} / \mathrm{kg})$ and MTX $(0.5 \mathrm{mg} / \mathrm{kg})$ decreased the arthritis global assessment in AA rats compared with normal rats $(P<0.01)$ (Figure 1A). From d 19 to d 35, BF02 $(9 \mathrm{mg} / \mathrm{kg})$ diminished the arthritis index $(P<0.01)$ (Figure 1B). On d 19 after immu- 

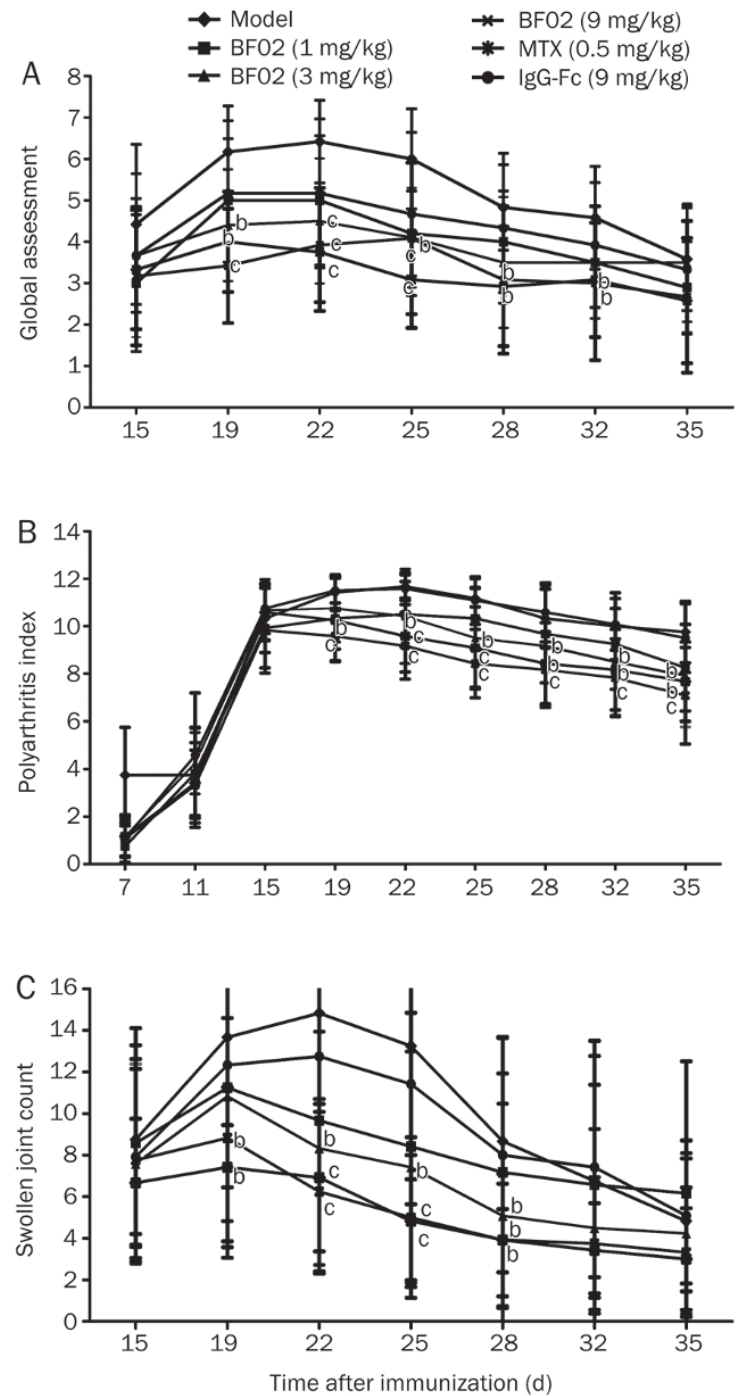

Figure 1. Effects of BFO2 on arthritis global assessment, arthritis index and swollen joint count. The onset of secondary arthritis of the disease appeared on d 11 after immunization, with a peak onset on d 20 to d 28 . (A) BFO2 $(9 \mathrm{mg} / \mathrm{kg})$ and MTX $(0.5 \mathrm{mg} / \mathrm{kg})$ could diminish arthritis global assessment significantly in rats with AA from d 22 to $d 25$. (B) BF02 (9 $\mathrm{mg} / \mathrm{kg}$ ) could inhibit arthritis index obviously in AA rats from d 19 to $\mathrm{d}$ 35. (C) Swollen joint count (SJC) increased in every group compared with the normal group, and the BF02 treatment group had marked changes compared with the model group. On d 22 to d 25 after immunization, BFO2 $(9 \mathrm{mg} / \mathrm{kg})$ and MTX $(0.5 \mathrm{mg} / \mathrm{kg})$ could diminish SJC obviously compared with the model group and IgG-Fc had no obvious effect on SJC. Data are expressed as mean \pm SEM from 12 animals for each group. ${ }^{\mathrm{b}} P<0.05,{ }^{\mathrm{c}} P<0.01$ vs model group.

nization, the swollen joint count increased in every group compared with the normal group, and the swollen joint count of the BF02 treatment group had a marked decrease compared with the model group $(P<0.05)$. From d 22 to d 25 after immunization, BF02 (9 mg/ kg) and MTX $(0.5 \mathrm{mg} / \mathrm{kg})$ clearly decreased the number of swollen joints $(P<0.01)$. IgG-Fc had no obvious effect on the swollen joint count (Figure 1C). These results suggest that $\mathrm{BF} 02$ administration attenuated the degree of arthritis and inhibited the progression of rat AA.

\section{Effects of BF02 on the radiological examination of the paws}

Compared with normal rats, radiographs from AA rats showed swelling of soft tissue, bone erosion and a narrow articular cavity. Radiographs from BF02 ( $9 \mathrm{mg} / \mathrm{kg})$ - and MTX $(0.5 \mathrm{mg} / \mathrm{kg})$-treated rats showed that the soft tissue swelling, bone erosion and narrow articular cavity were ameliorated. The radiograph scores of the model rats were higher than in the normal rats. BF02 (9 mg/ $\mathrm{kg})$ and MTX $(0.5 \mathrm{mg} / \mathrm{kg})$

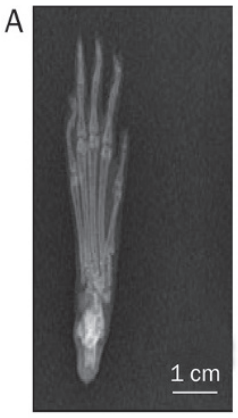

Normal

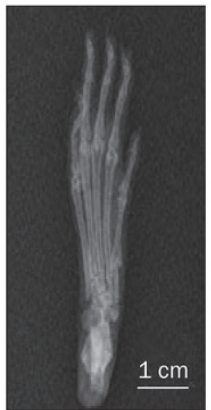

BF02

(9 mg/kg)

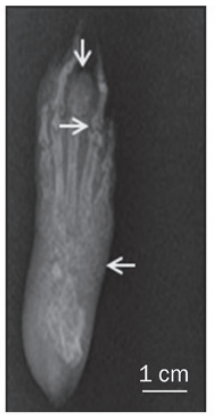

AA

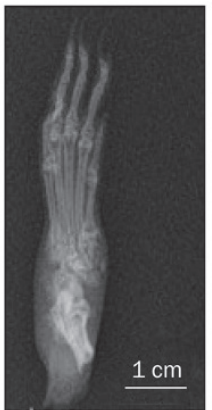

MTX (0.5 mg/kg)

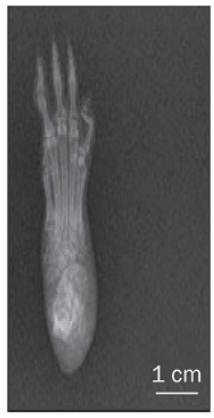

BFO2 $(1 \mathrm{mg} / \mathrm{kg})$

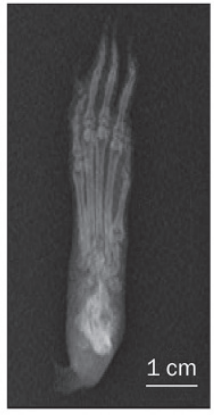

IgG-Fc (9 mg/kg)

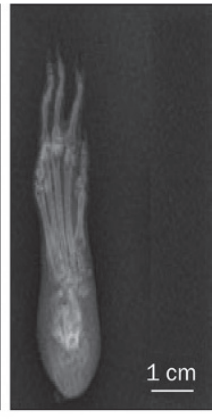

$\mathrm{BFO} 2$ (3 mg/kg)
B

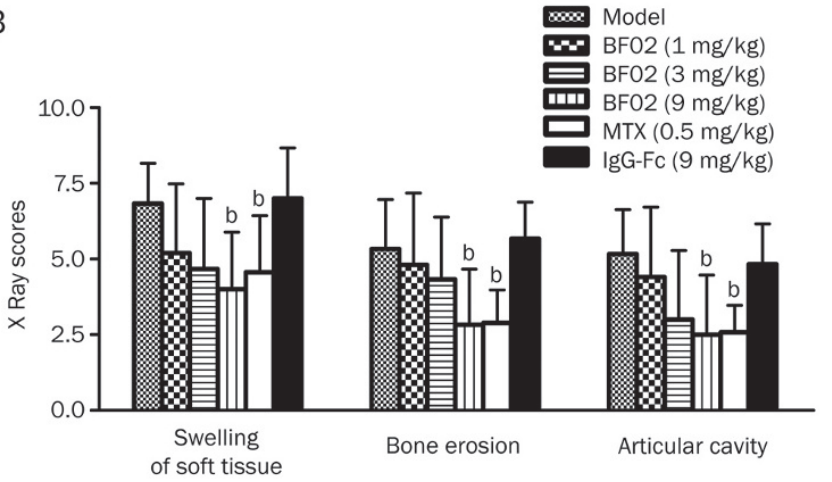

Figure 2. Effects of BFO2 on radiological examination of paws. (A) Radiographs of AA model group showed swelling of soft tissue, bone erosion and narrow articular cavity compared with the normal group. (B) BF02 $(9 \mathrm{mg} / \mathrm{kg})$ and MTX $(0.5 \mathrm{mg} / \mathrm{kg})$ could significantly reduce the increased radiograph scores, and IgG-Fc had no obvious effect on radiograph scores. Data are expressed as mean \pm SEM from 12 animals for each group. ${ }^{b} P<0.05,{ }^{c} P<0.01$ vs model group. 
reduced the high radiograph scores $(P<0.05)$; however, IgG-Fc had no obvious effect on the radiograph scores (Figure 2A, 2B).

\section{Effects of BF02 on the ankle joint histopathology}

The histopathology of ankle joints in AA rats showed multiple layers of synovium hyperplasia with pannus, cartilage erosion and inflammatory cell infiltration. The scores for synovium hyperplasia, cell infiltration, pannus, cartilage and bone erosion were increased in AA rats compared with the normal group (Figure $3 \mathrm{~A}$ ). In contrast, the administration of BF02 ameliorated these abnormalities $(P<0.05)$. AA rats treated with BF02 $(9 \mathrm{mg} / \mathrm{kg})$ and MTX $(0.5 \mathrm{mg} / \mathrm{kg})$ showed only minimal inflammation and pathological changes: bone erosion and degradation were scarcely detected; inflammatory cell infiltration was also obviously reduced; and the high pannus scores were decreased (Figure 3B). IgG-Fc had no obvious effect.

\section{Effects of BF02 on the spleen histopathology}

In AA rats, white pulp proliferation, germinal centers and red pulp hyperemia were observed. BF02 (3 and $9 \mathrm{mg} / \mathrm{kg}$ ) and
MTX $(0.5 \mathrm{mg} / \mathrm{kg})$ significantly alleviated these abnormalities to varying degrees (Figure 4A). The scores for cell density lymphatic sheath, lymphoid follicular hyperplasia, marginal zone and red pulp were significantly higher in the AA rats than in the normal rats. BF02 $(9 \mathrm{mg} / \mathrm{kg})$ diminished the scores for cell density lymphatic sheath, lymphoid follicular hyperplasia, marginal zone and red pulp $(P<0.01)$ (Figure 4B). No significant changes were observed in the IgG-Fc group.

These results suggest that $\mathrm{BF} 02$ had a therapeutic effect on rat AA. Were the therapeutic effects of BF02 on the study animals related to regulating T lymphocyte function? To answer this question, the effects of BF02 on the proliferation, cytokines and subsets of $\mathrm{T}$ lymphocytes were analyzed further.

\section{Effects of BF02 on T lymphocyte proliferation}

The results showed that the ConA-induced T lymphocyte proliferation in the model group was increased compared with the normal group $(P<0.05)$. BF02 $(3$ and $9 \mathrm{mg} / \mathrm{kg})$ and MTX $(0.5 \mathrm{mg} / \mathrm{kg})$ reduced $\mathrm{T}$ lymphocyte proliferation in the AA rats compared with the normal rats $(P<0.05)$. IgG-Fc had no obvious effect on $\mathrm{T}$ lymphocyte proliferation (Figure 5).
A
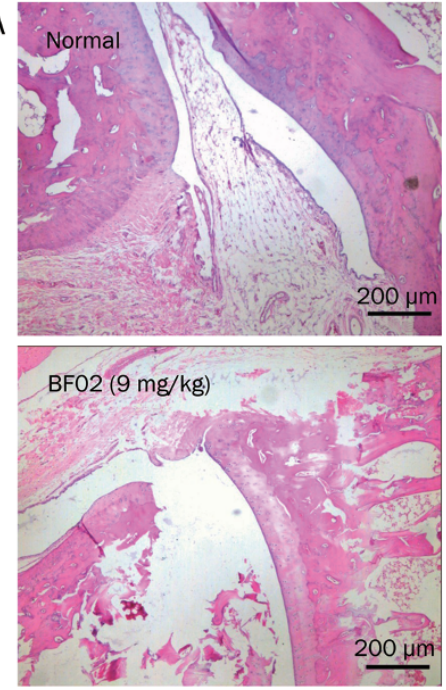
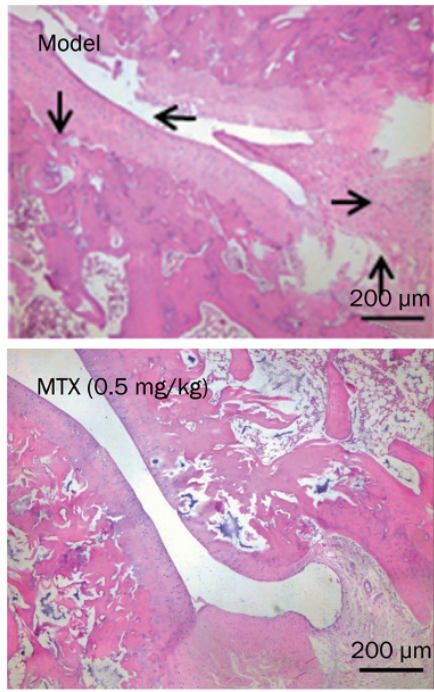
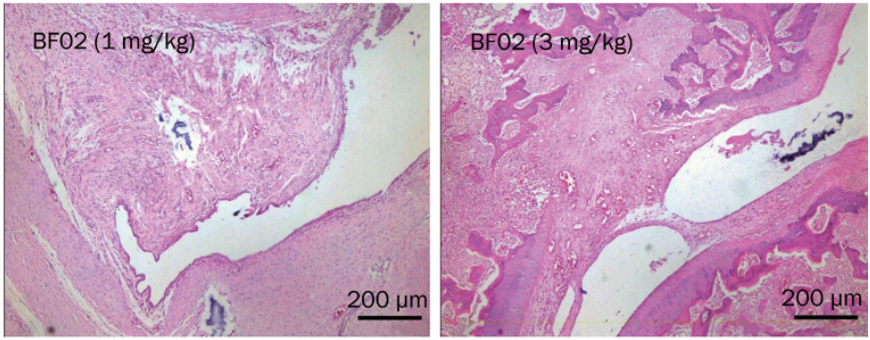

B

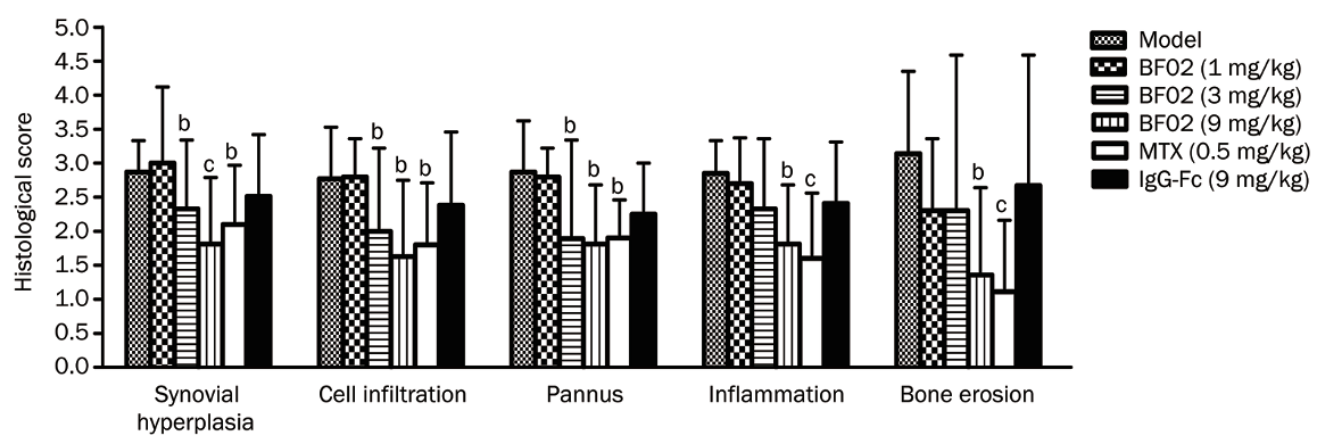

Figure 3. Effects of BFO2 on ankle joint histopathology. (A) Compared to the normal group, the model group showed marked synovium hyperplasia, cellular infiltration, pannus formation, bone erosion and inflammation (HE staining, $\times 40)$. (B) BF02 (9 mg/kg) and MTX (0.5 mg/kg) showed only minimal inflammation and pathological changes: bone erosion and degradation were scarcely detected, inflammatory cell infiltration was also obviously reduced, and the increased scores of pannus were decreased. IgG-Fc had no obvious effect. Data are expressed as mean \pm SEM from 12 animals for each group. ${ }^{\mathrm{b}} P<0.05,{ }^{\mathrm{c}} P<0.01$ vs model group. 
A
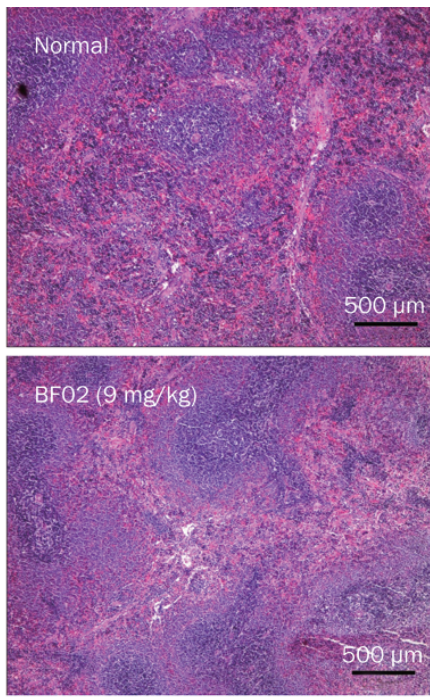
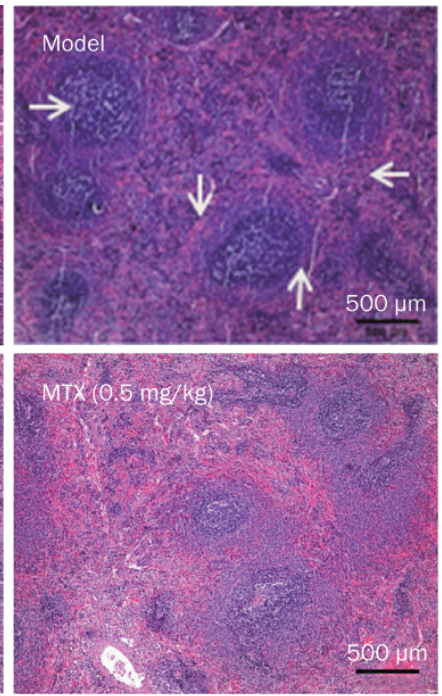
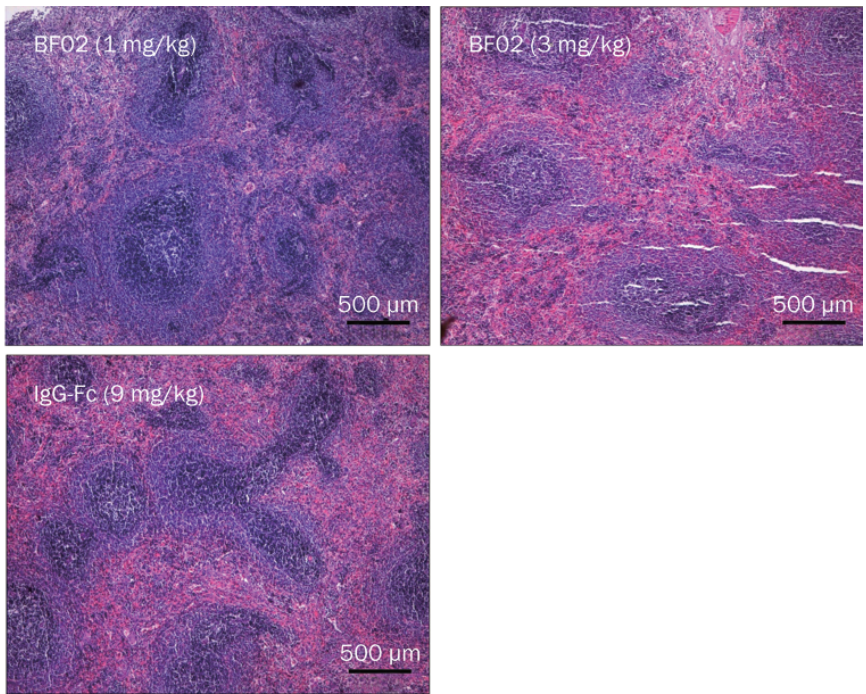

B

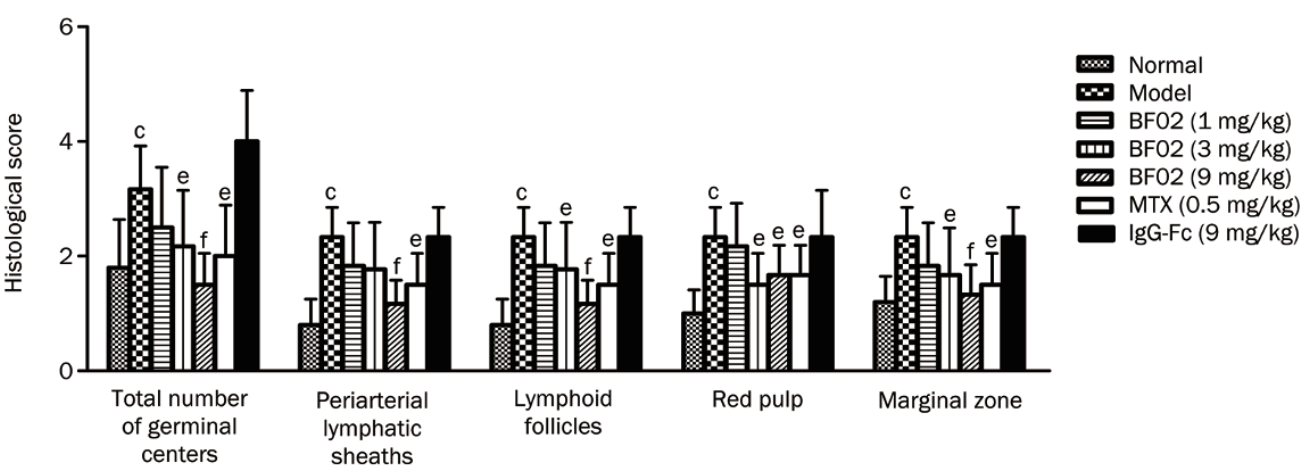

Figure 4. Effects of BFO2 on spleen histopathology. (A) In AA rats, proliferated white pulp, emerged germinal centers, and red pulp hyperemia, infiltrated spleens with inflammatory cells (HE staining, $\times 40)$. BFO2 (3 and $9 \mathrm{mg} / \mathrm{kg}$ ) and MTX (0.5 mg/kg) significantly alleviated these abnormal changes. (B) BFO2 (3 and $9 \mathrm{mg} / \mathrm{kg})$ and MTX $(0.5 \mathrm{mg} / \mathrm{kg})$ diminished the scores of cell density lymphatic sheath, lymphoid follicular hyperplasia, marginal zone and red pulp. There were no significant changes in IgG-Fc group. Data are expressed as mean \pm SEM from 12 animals for each group. ${ }^{\mathrm{c}} P<0.01$ vs normal group. ${ }^{\mathrm{e}} P<0.05,{ }^{\mathrm{f}} P<0.01$ vs model group.

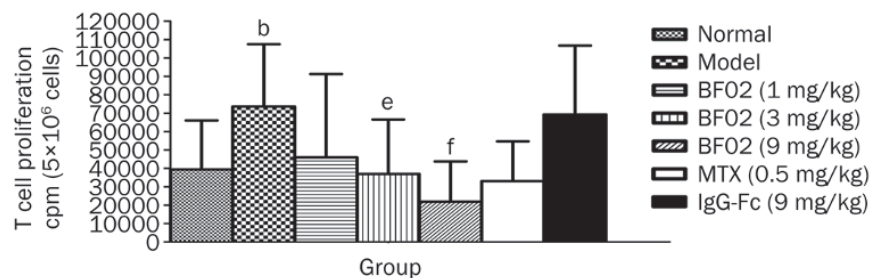

Figure 5. Effects of BFO2 on T lymphocyte proliferations. Results showed that ConA-induced $\mathrm{T}$ lymphocyte proliferation in AA group was increased. BFO2 (3 and $9 \mathrm{mg} / \mathrm{kg}$ ) and MTX (0.5 mg/kg) could reduce T lymphocyte proliferations. IgG-Fc had no obvious effect on T lymphocyte proliferations. Data are expressed as mean \pm SEM from 12 animals for each group. ${ }^{\mathrm{b}} P<0.05$ vs normal group. ${ }^{\mathrm{e}} P<0.05,{ }^{\mathrm{f}} P<0.01$ vs model group.

Effects of BF02 on IL-1, IL-6, IL-17, TNF- $\alpha$, LT $\alpha$, RANKL, and MMP13 in serum

The results showed that the levels of IL-1, IL-6, IL-17, LTa, TNF-a, MMP-13, and RANKL in serum were increased in the rat $\mathrm{AA}$ group in comparison to the normal group. The administration of BF02 $(3$ and $9 \mathrm{mg} / \mathrm{kg})$ and MTX $(0.5 \mathrm{mg} / \mathrm{kg})$ obviously decreased the production of IL-1, IL-6, IL-17, LTa, TNF- $a$, and MMP-13. BF02 $(9 \mathrm{mg} / \mathrm{kg})$ also reduced the level of RANKL. IgG-Fc had no obvious effect on the cytokine levels (Figure 6A-6D).

Effects of BF02 on IL-17 and TNF- $\alpha$ mRNA expression in the thymus

The results indicated that the mRNA expression of IL-17 and TNF-a was increased in AA rats and that BF02 $(9 \mathrm{mg} / \mathrm{kg})$ reduced the expression of these mRNAs $(P<0.01)$ (Figure 7).

Effects of BF02 on the subsets of T lymphocytes in the spleen The subsets of $\mathrm{T}$ lymphocytes were assayed by flow cytometry. The percentages and numbers of $\mathrm{CD} 3^{+} \mathrm{CD} 4^{+}$and $\mathrm{CD} 44^{+} \mathrm{CD} 25^{+}$ $\mathrm{T}$ lymphocytes were higher in the AA rats than in the normal rats. The $\mathrm{CD}^{+} \mathrm{CD} 62 \mathrm{~L}^{+} \mathrm{T}$ lymphocyte counts were lower in the AA rats than in the normal rats. BF02 $(1,3$, and $9 \mathrm{mg} / \mathrm{kg})$ and MTX $(0.5 \mathrm{mg} / \mathrm{kg})$ decreased the percentage of $\mathrm{CD} 4^{+} \mathrm{CD} 25^{+}$ 
A

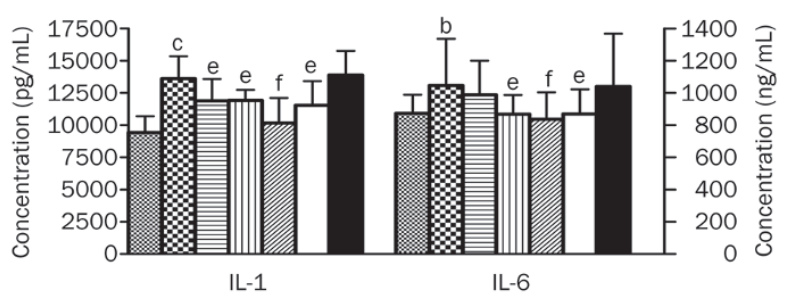

C

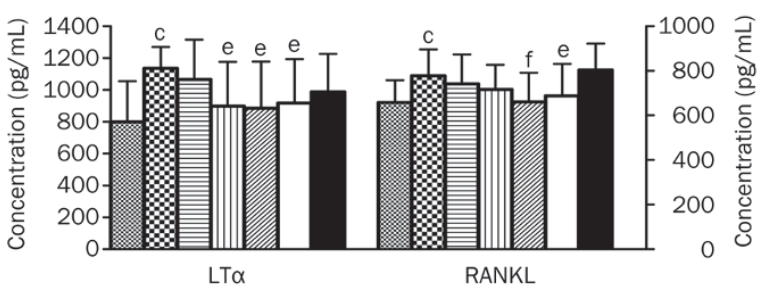

B

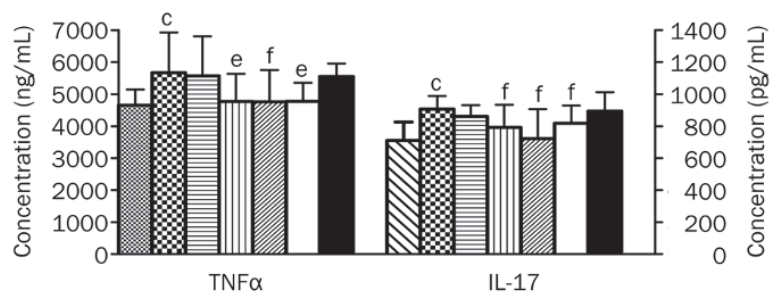

D

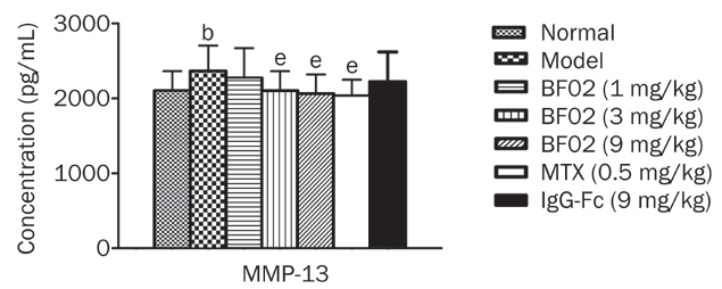

Figure 6. Effects of BFO2 on the levels of TNF- $\alpha$, IL-1, IL-6, IL-17, LT $\alpha$, RANKL, and MMP-13 in serum of AA. Results showed that the level of (A) IL-1 and IL-6, ( B) TNF- $\alpha$ and IL-17, (C) LT $\alpha$ and RANKL and (D) MMP-13 was increased in the model group compared to the normal group. The administration of BF02 (3 and 9mg/kg) and MTX (0.5 mg/kg) significantly decreased the production of IL-1, IL-6, IL-17, LT $\alpha$, TNF- $\alpha$, and MMP-13. BF02 (9 mg/kg) could reduce the level of RANKL. IgG-Fc had no obvious effect on the level of cytokines. Data are expressed as mean \pm SEM from 12 animals for each group. ${ }^{\mathrm{b}} P<0.05,{ }^{\mathrm{c}} P<0.01$ vs normal group. ${ }^{\mathrm{e}} P<0.05,{ }^{\mathrm{f}} P<0.01$ vs model group.
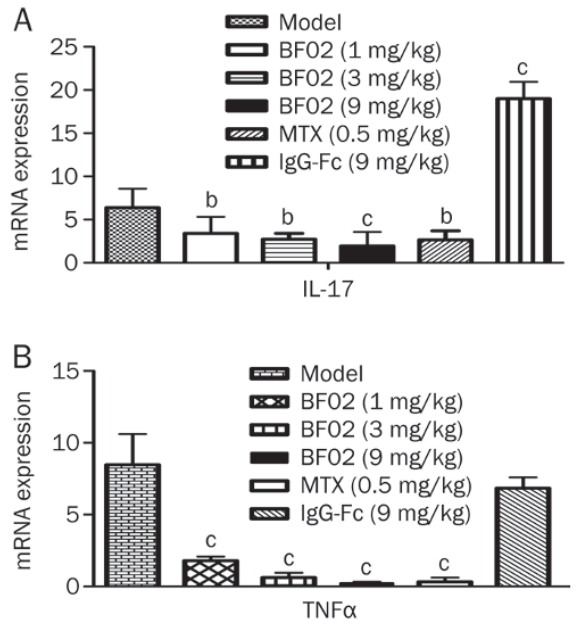

Figure 7. Effects of BFO2 on IL-17 and TNF- $\alpha$ mRNA expression in T lymphocytes. The mRNA levels of (A) IL-17 and (B) TNF- $\alpha$ were increased in $\mathrm{T}$ lymphocytes of AA. The expression mRNA levels of IL-17 and TNF- $\alpha$ were significantly reduced in BFO2-treated rats. Data are expressed as mean \pm SEM. ${ }^{b} P<0.05,{ }^{c} P<0.01$ vs model group.

T lymphocytes. BF02 (3 and $9 \mathrm{mg} / \mathrm{kg})$ and MTX $(0.5 \mathrm{mg} / \mathrm{kg})$ also restored the percentage of $\mathrm{CD} 44^{+} \mathrm{CD} 62 \mathrm{~L}^{+} \mathrm{T}$ lymphocytes (which is low in AA rats) to normal levels, whereas BF02 (1, 3 , and $9 \mathrm{mg} / \mathrm{kg}$ ) had no obvious effect on the percentage of $\mathrm{CD}^{+} \mathrm{CD}^{+} \mathrm{T}$ lymphocytes (Figure 8).

Effects of BF02 on the $\mathrm{CD}^{+} \mathrm{CD}^{2} 5^{+} \mathrm{FoxP}^{+} \mathrm{T}$ lymphocytes in the spleens of $A A$ rats

Compared to the normal group, the percentage of
$\mathrm{CD}^{+} \mathrm{CD} 25^{+} \mathrm{FoxP}^{+} \mathrm{T}$ lymphocytes was obviously lower in the AA group. BF02 $(9 \mathrm{mg} / \mathrm{kg})$ restored the percentage of $\mathrm{CD}^{+} \mathrm{CD} 25^{+} \mathrm{FoxP}^{+} \mathrm{T}$ cells to normal levels $(P<0.05)$ (Figure 9).

\section{Discussion}

RA is a chronic and systemic autoimmune disorder that is characterized by pain, swelling, stiffness of multiple joints and inflammatory cell infiltration ${ }^{[18,19]}$. AA is a classical animal model for investigating the pathology of RA and drug therapy for RA. The characteristics of AA, such as joint swelling, lymphocyte infiltration, and cartilage degradation, are shared with human $\mathrm{RA}^{[20]}$.

In the present study, it was found that the early pro-inflammatory components of the local inflammatory response were primary symptoms in rat AA. In the course of the disease, the secondary hind paws swelled, and "arthritis" tubercles of the ears, nodes and base of the tail appeared, accompanied by decreased physical activity and weight loss in the AA rats.

BF02 significantly suppressed secondary hindpaw swelling, decreased the arthritis index, and reduced histopathological injuries of the joints and spleen. Moreover, BF02 reduced the extent of radiological changes to the paws of AA rats. These findings suggest that $\mathrm{BF} 02$ has therapeutic activity in AA rats.

The role of $T$ cells in the pathogenesis of RA is well established. Activated T cells found in the synovial fluid of RA patients can directly activate macrophages, synoviocytes and osteoclasts by cell-to-cell interactions ${ }^{[21]}$. The RA disease process is thought to be dependent on a trimolecular complex consisting of antigenic peptides, $\mathrm{T}$ cell receptors and HLA$\mathrm{DR} 4^{[22]}$. T cells combine with the complex and become activated. Activated $\mathrm{T}$ cells begin to release cytokines, such as TNF-a, IL-1, IL-6, IL-17, LTa, RANKL and MMP-13. 


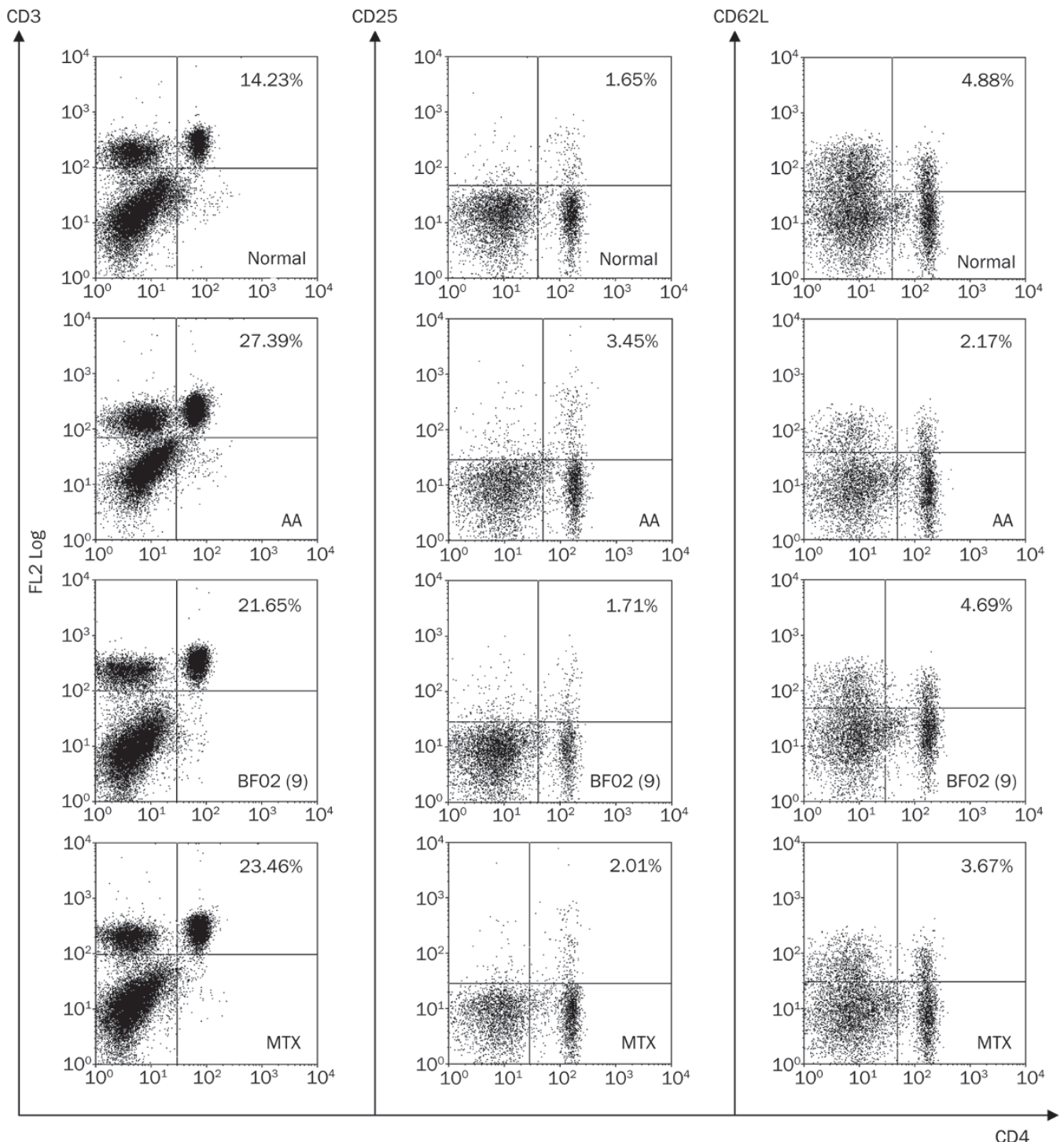

Figure 8. Effects of BFO2 on the subsets of T lymphocytes in spleen. According to flow cytometry analysis, the model group had a higher percent of $\mathrm{CD}^{+} \mathrm{CD} 4^{+}$and $\mathrm{CD} 4^{+} \mathrm{CD} 25^{+} \mathrm{T}$ lymphocytes in spleen than the normal group. $\mathrm{CD} 4^{+} \mathrm{CD} 62 \mathrm{~L}^{+} \mathrm{T}$ lymphocytes were reduced in model group. BF02 (1, 3 , and $9 \mathrm{mg} / \mathrm{kg}$ ) and MTX $\left(0.5 \mathrm{mg} / \mathrm{kg}\right.$ ) could inhibit the percentage of CD4 ${ }^{+} \mathrm{CD} 25^{+}$T lymphocytes. Moreover, BFO2 (3 and $\left.9 \mathrm{mg} / \mathrm{kg}\right)$ and MTX (0.5 mg/kg) could restore the decreased percentage of $\mathrm{CD}^{+} \mathrm{CD} 62 \mathrm{~L}^{+} \mathrm{T}$ lymphocytes.

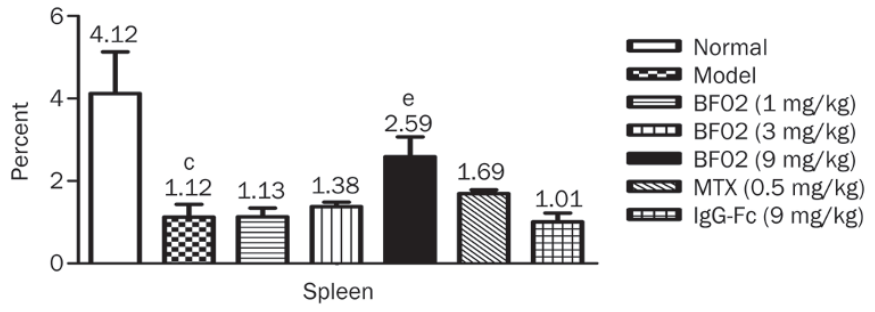

Figure 9. Effects of BFO2 on the $\mathrm{CD} 4^{+} \mathrm{CD} 25^{+} \mathrm{FoxP} 3^{+} \mathrm{T}$ lymphocytes spleen in AA rats. Compared to the normal group, the percentage of $\mathrm{CD} 4^{+} \mathrm{CD} 25^{+} \mathrm{FoxP}^{+} \mathrm{T}$ lymphocytes decreased obviously in the model group. BFO2 $(9 \mathrm{mg} / \mathrm{kg})$ could restore the decreased percentage of $\mathrm{CD}^{+} \mathrm{CD}^{+} 5^{+} \mathrm{FoxP}^{+} \mathrm{T}$ cells. Data are expressed as mean $\pm \mathrm{SEM}$ from 12 animals for each group. ${ }^{c} P<0.01$ vs normal group. ${ }^{\mathrm{e}} P<0.05$ vs model group.
TNF-a has pleiotropic effects that drive the immune response, with powerful modulatory effects on many aspects of cellular and humoral immunity ${ }^{[23,24]}$. TNF-a plays an important role in $\mathrm{RA}^{[25]}$ and may affect earlier stages of the autoimmune process, such as $\mathrm{T}$ cell activation and differentiation into effector subsets. Furthermore, TNF-a is involved in the activation of synovial fibroblasts. LTa is a pro-inflammatory cytokine that is mainly produced by $\mathrm{T}$ and $\mathrm{B}$ lymphocytes and that mediates a large variety of inflammatory responses ${ }^{[26,27]}$. LTa has significant homology to TNF- $a$, which binds specifically to TNFR1 and TNFR2 ${ }^{[28]}$. RANKL is a member of the TNF family, is a ligand for osteoprotegerin and functions as a key factor for osteoclast differentiation and activation ${ }^{[29]}$. RANKL is expressed by $\mathrm{T}$ helper 
cells and is thought to be involved in dendritic cell maturation. IL-17 is also a pro-inflammatory cytokine that plays an important role in autoimmune experimental arthritis by aggravating synovial inflammation and joint destruction ${ }^{[30,31]}$. Moreover, this enhanced IL-17 signaling results in increased expression of downstream pro-inflammatory targets, such as IL- $6^{[32,33]}$. IL-6 and IL- 1 are the key inflammatory cytokines, and there is compelling evidence that tissue destruction and joint inflammation are regulated by IL- 1 and IL- $6^{[34]}$. IL- 6 stimulates B and $\mathrm{T}$ cell differentiation and activation, as well as immunoglobulin production. These key inflammatory cytokines induce inflammation and release MMP-13, which degrades type II collagen and is involved in pannus formation ${ }^{[35]}$. The present study showed that the proliferation of $\mathrm{T}$ lymphocytes was enhanced and that the levels of TNF-a, LTa, RANKL, IL-17, IL-1, IL-6, and MMP-13 increased significantly in the serum of AA rats. BF02 inhibited T lymphocyte proliferation and decreased the elevated levels of the above cytokines. In conclusion, these results show that BF02 plays an antiinflammatory role in AA by reducing the levels of IL-1, IL-6, IL-17, LTa, TNF-a, RANKL, and MMP-13.

To provide further support for our conclusion, we also measured the mRNA expression of TNF- $\alpha$ and IL-17, which play key roles in regulating $\mathrm{T}$ cell function. In our research, higher levels of IL-17 mRNA and TNF- $\alpha$ mRNA were found in AA rats than in normal rats. This result was consistent with the functions of TNF- $\alpha$ and IL-17 levels in serum. Taken together, BF02 down-regulates pro-inflammatory cytokines, indicates that it might regulate $\mathrm{T}$ cell function.

Auto-reactive $\mathrm{CD} 4^{+}$cells play a major role in $\mathrm{RA}^{[36]}$. Analysis of $\mathrm{T}$ cells from AA rats showed an increase in $\mathrm{CD}^{+} \mathrm{CD} 4^{+}$ cells and $\mathrm{CD} 4^{+} \mathrm{CD} 25^{+} \mathrm{T}$ cells. However, the percentage of $\mathrm{CD}^{+} \mathrm{CD} 2 \mathrm{~L}^{+}$(analogous to naïve) $\mathrm{T}$ cells was decreased. Furthermore, BF02 down-regulated the activation of $\mathrm{T}$ cells and up-regulated that of naïve $\mathrm{T}$ cells but had no obvious effect on the percentage of $\mathrm{CD}^{+} \mathrm{CD} 4^{+}$cells. These results demonstrate that $\mathrm{BF} 02$ regulated the $\mathrm{T}$ cell immune response by inhibiting the differentiation and activation of $\mathrm{CD} 4^{+} \mathrm{T}$ cells instead of reducing the counts of $\mathrm{CD} 4^{+} \mathrm{T}$ cells. $\mathrm{CD} 4^{+} \mathrm{CD} 25^{+} \mathrm{Foxp} 3^{+}$ Treg cells control the responses of APC and effector T cells in the periphery through direct interaction with these cells or through anti-inflammatory cytokines ${ }^{[37]}$ and play an important role in limiting inflammation and regulating adaptive immunity ${ }^{[38]}$. Our results show that the percentage of $\mathrm{CD}^{+} \mathrm{CD} 25^{+} \mathrm{Foxp}^{+} \mathrm{T}$ lymphocytes was lower in the AA group and that $\mathrm{BF} 02$ was able to restore the percentage of $\mathrm{CD} 4^{+} \mathrm{CD} 25^{+} \mathrm{Foxp}^{+} \mathrm{T}$ lymphocytes.

Currently, etanercept is used to treat RA. However, $25 \%$ to $38 \%$ of patients show no response, which may be due, in part, to the insufficient affinity of this protein for TNF- $\mathrm{a}^{[39,40]}$. In addition, adverse reactions of etanercept include infection and non-infection-related adverse reactions, such as tumors, cardiac insufficiency, and nervous system lesions ${ }^{[41]}$. Compared to etanercept, the concentration of BF02 was higher and the generation of byproducts was lower with BF02. Therefore, the adverse reactions of BF02 may be fewer.
In conclusion, the present study suggests that the abnormal activity of $\mathrm{T}$ lymphocytes plays a crucial role in the pathogenesis of AA and that BF02 has therapeutic effects on rat AA, as indicated by the decreasing arthritis index, swollen joint count and arthritis global assessment and improved paw X-rays, ankle joint histopathology and spleen histopathology. The therapeutic effects might be related to the ability of BF02 to down-regulate pro-inflammatory cytokines and up-regulate regulatory $\mathrm{T}$ cells by blocking the function of TNF- $\alpha$.

\section{Acknowledgements}

This work was supported by the National Natural Science Foundation of China (№ 30973543, 31100640, and 81173075) and the Anhui Province Natural Science Foundation (№ 11040606M195).

\section{Author contribution}

Wei WEI, Ling-ling ZHANG, and Qing-tong WANG designed the research; Shan-shan SONG, Bei HUANG, Yu-jing WU, Jing-jing FU, Yun-fang ZHANG, Yan CHANG, Jing-yu CHEN, Hua-xun WU, Di WANG, and Ling-ling ZHANG performed the research; Shan-shan SONG, Yu-jing WU, and Ling-ling ZHANG analyzed the data; and Shan-shan SONG wrote the paper.

\section{References}

1 Jawaheer D, Lum RF, Gregersen PK, Criswell LA. Influence of male sex on disease phenotype in familial rheumatoid arthritis. Arthritis Rheum 2006; 54: 3087-94.

2 Yan Z, Ferucci ED, Geraghty DE, Yang Y, Lanier AP, Smith WP, et al. Resequencing of the human major histocompatibility complex in patients with rheumatoid arthritis and healthy controls in Alaska Natives of Southeast Alaska. Tissue Antigens 2007; 70: 487-94.

3 Nam J, Emery P. Aspects of TNF inhibitor therapy in rheumatoid arthritis. Mod Rheumatol 2010; 20: 325-30.

4 Connor AM, Mahomed N, Gandhi R, Keystone EC, Berger SA. Tumor necrosis factor-alpha modulates protein degradation pathways in RA synovial fibroblasts. Arthritis Res Ther 2012; 14: R62.

5 Bradley JR. TNF-mediated inflammatory disease. J Pathol 2008; 214 : 149-60.

6 Wong M, Ziring D, Korin Y, Desai S, Kim S, Lin J, et al. TNFalpha blockade in human diseases: mechanisms and future directions. Clin Immunol 2008; 126: 121-36.

7 Gumà Uriel M. Animal models in rheumatoid arthritis. Reumatol Clin 2008; 4: 129-31.

8 Tracey D, Klareskog L, Sasso EH, Salfeld JG, Tak PP. Tumor necrosis factor antagonist mechanisms of action: a comprehensive review. Pharmacol Ther 2008; 117: 244-79.

9 Wooley PH, Dutcher J, Widmer MB, Gillis S. Influence of a recombinant human soluble tumor necrosis factor receptor FC fusion protein on type II collagen-induced arthritis in mice. J Immunol 1993; 151: 6602-7.

10 Moreland LW, Baumgartner SW, Schiff MH, Tindall EA, Fleischmann RM, Weaver AL, et al. Treatment of rheumatoid arthritis with a recombinant human tumor necrosis factor receptor ( $p 75)$-Fc fusion protein. N Eng J Med 1997; 337: 141-7.

11 Hegen M, Keith JC Jr, Collins M, Nickerson-Nutter CL. Utility of animal models for identification of potential therapeutics for rheumatoid arthritis. Ann Rheum Dis 2008; 67: 1505-15. 
12 Wang D, Chang Y, Wu Y, Zhang L, Yan S, Xie G, et al. Therapeutic effects of TACl-Ig on rat with adjuvant arthritis. Clin Exp Immunol 2011; 163: 225-34.

13 Wu H, Wei W, Song L, Zhang L, Chen Y, Hu X. Paeoniflorin induced immune tolerance of mesenteric lymph node lymphocytes via enhancing beta 2-adrenergic receptor desensitization in rats with adjuvant arthritis. Int Immunopharmacol 2007; 7: 662-73.

14 Chang Y, Wu Y, Wang D, Wei W, Qin Q, Xie G, et al. Therapeutic effects of TACl-Ig on rats with adjuvant-induced arthritis via attenuating inflammatory responses. Rheumatology (Oxford) 2011; 50: 862-70.

15 Wang QT, Ma YK, Huang B, Liu DD, Wei W. Effect of rhTACl-lg fusion protein on antigen-specific $T$ cell responses from keyhole limpet haemocyanin challenged mice. Mol Immunol 2011; 49: 380-6.

16 Germolec DR, Nyska A, Kashon M, Kuper CF, Portier C, Kommineni $\mathrm{C}$, et al. Extended histopathology in immunotoxicity testing: interlaboratory validation studies. Toxicol Sci 2004; 78: 107-15.

17 Schmittgen TD, Livak KJ. Analyzing real-time PCR data by the comparative $C_{T}$ method. Nat Protoc 2008; 3: 1101-8.

18 Fekete A, Soos L, Szekanecz Z, Szabo Z, Szodoray P, Barath S, et al. Disturbances in $\mathrm{B}$ - and T-cell homeostasis in rheumatoid arthritis: suggested relationships with antigen-driven immune responses. J Autoimmun 2007; 29: 154-63.

19 Anderton SM, Fillatreau S. Activated B cells in autoimmune diseases: the case for a regulatory role. Nat Clin Pract Rheumatol 2008; 4: 657-66.

20 Bevaart L, Vervoordeldonk MJ, Tak PP. Evaluation of therapeutic targets in animal models of arthritis: how does it relate to rheumatoid arthritis? Arthritis Rheum 2010; 62: 2192-205.

21 Tran CN, Lundy SK, Fox DA. Synovial biology and T cells in rheumatoid arthritis. Pathophysiology 2005; 12: 183-9.

22 Panayi GS. B cells: a fundamental role in the pathogenesis of rheumatoid arthritis? Rheumatology (Oxford) 2005; 44: 3-7.

23 Feldmann M, Maini RN. Anti-TNF therapy, from rationale to standard of care: what lessons has it taught us? J Immunol 2010; 185: 791-4.

24 Choo-Kang BS, Hutchison S, Nickdel MB, Bundick RV, Leishman AJ, Brewer JM, et al. TNF-blocking therapies: an alternative mode of action? Trends Immunol 2005; 26: 518-22.

25 Raza K, Buckley CE, Salmon M, Buckley CD. Treating very early rheumatoid arthritis. Best Pract Res Clin Rheumatol 2006; 20: 84963.

26 Calmon-Hamaty F, Combe B, Hahne M, Morel J. Lymphotoxin $\alpha$ stimulates proliferation and pro-inflammatory cytokine secretion of rheumatoid arthritis synovial fibroblasts. Cytokine 2011; 53: 207-14.

27 Chiang EY, Kolumam GA, Yu X, Francesco M, Ivelja S, Peng I, et al. Targeted depletion of lymphotoxin-alpha-expressing TH1 and TH17 cells inhibits autoimmune disease. Nat Med 2009; 15: 766-73.
28 Schneider K, Potter KG, Ware CF. Lymphotoxin and LIGHT signaling pathways and target genes. Immunol Rev 2004; 202: 49-66.

29 Dayer Schneider J, Seibold I, Saxer-Sekulic N, Paredes BE, Saurer L, Mueller C. Lack of TNFR2 expression by $\mathrm{CD}^{+} \mathrm{T}$ cells exacerbates experimental colitis. Eur J Immunol 2009; 39: 1743-53.

30 Pinto LG, Cunha TM, Vieira SM, Lemos HP, Verri WA Jr, Cunha FQ, et al. IL-17 mediates articular hypernociception in antigen-induced arthritis in mice. Pain 2010; 148: 247-56.

31 Harrington LE, Hatton RD, Mangan PR, Turner H, Murphy TL, Murphy $\mathrm{KM}$, et al. Interleukin 17-producing $\mathrm{CD}^{+}$effector T cells develop via a lineage distinct from the Thelper type 1 and 2 lineages. Nat Immunol 2005; 6: 1123-32.

32 Roşu A, Mărgăritescu C, Stepan A, Muşetescu A, Ene M. IL-17 patterns in synovium, serum and synovial fluid from treatment-naïve, early rheumatoid arthritis patients. Rom J Morphol Embryol 2012; 53: 73-80.

33 Sarkar S, Fox DA. Targeting IL-17 and Th17 cells in rheumatoid arthritis. Rheum Dis Clin North Am 2010; 36: 345-66.

34 Hasan E, Olusi S, Al-Awadhi A, Mokaddem K, Sharma P, George $S$. Effects of rituximab treatment on the serum concentrations of vitamin D and interleukins 2, 6, 7, and 10 in patients with rheumatoid arthritis. Biologics 2012; 6: 31-5.

35 Vincenti MP, Brinckerhoff CE. Transcriptional regulation of collagenase (MMP-1, MMP-13) genes in arthritis: integration of complex signaling pathways for the recruitment of gene-specific transcription factors. Arthritis Res 2002; 4: 157-64.

36 Bettelli $\mathrm{E}$, Oukka $\mathrm{M}$, Kuchroo VK. $\mathrm{T}_{\mathrm{H}}-17$ cells in the circle of immunity and autoimmunity. Nat Immunol 2007; 8: 345-50.

37 Walker MR, Kasprowicz DJ, Gersuk VH, Benard A, Van Landeghen M, Buckner $\mathrm{JH}$, et al. Induction of FoxP3 and acquisition of T regulatory activity by stimulated human $\mathrm{CD}^{+} \mathrm{CD} 25^{-} \mathrm{T}$ cells. J Clin Invest 2003; 112: $1437-43$.

38 Chavele KM, Ehrenstein MR. Regulatory T-cells in systemic lupus erythematosus and rheumatoid arthritis. FEBS Lett 2011; 585: 3603-10.

39 Saag KG, Teng GG, Patkar NM, Anuntiyo J, Finney C, Curtis JR, et al. American College of Rheumatology 2008 recommendations for the use of nonbiologic and biologic disease-modifying antirheumatic drugs in rheumatoid arthritis. Arthritis Rheum 2008; 59: 762-84.

40 Yang T, Wang Z, Wu F, Tan J, Shen Y, Li E, et al. A variant of TNFR2Fc fusion protein exhibits improved efficacy in treating experimental rheumatoid arthritis. PLoS Comput Biol 2010; 6: e1000669.

41 Salgado E, Gómez-Reino JJ. The risk of tuberculosis in patients treated with TNF antagonists. Expert Rev Clin Immunol 2011; 7: 329-40. 